Journal of Mathematics and Statistics 6 (4): 431-441, 2010

ISSN 1549-3644

(C) 2010 Science Publications

\title{
Modeling Tourist Arrivals in Destination Countries: An Application to Australian Tourism
}

\author{
${ }^{1}$ S.A.H. Shobeiri Nejad and ${ }^{2}$ Gurudeo Anand Tularam \\ ${ }^{1}$ Department of Mathematics and Statistics, Environment Futures Centre, \\ ${ }^{2}$ Faculty of Science Environment Engineering and Technology (ENV), \\ Griffith University, Brisbane Australia
}

\begin{abstract}
Problem statement: Little study is evident of mathematical modeling regarding tourist arrivals in South East Queensland of Australia. In this study the Bulter conceptual destination life cycle and product life cycle frameworks are used to develop an overall determinant mathematical model of Australian tourist arrivals. The model will be calibrated using real Australian data. A more complex dynamic is also being considered and will be reported later. Approach: In the main, a modeling approach with derivative calculus was used to develop the model and identify the stages of the framework: namely; periods of exploration, involvement, development, consolidation and stagnation stages. A logistic modeling approach is also used. Results: The conceptual model led to an exponential solution and using logistic technique minimizing error led to an exponential model that fit the data well (adj $r^{2}=0.99$ ). The model predicts Australian arrivals to be 7.2 million arrivals in 2015. Each of the periods suggested in the literature was identified. A healthy rejuvenation rate of 0.144 was also noted rather useful for forward planners and government departments focused on enhancing Australia's share of international tourist arrivals. Conclusion: The international arrivals to Australia have grown significantly since 1974 and the growth has a logistic trend as predicted by the theoretical model. The stagnation stage is probably yet to be reached thus many opportunities exist for the tourism industry; the Australian arrival proportion compared to the world is around $0.061 \%$ suggesting much can be done to attract the tourist dollars; in critical region and the period before stagnation, Australia will have a growth at least equal to the world's rate. According to UNWTO, the world has a growth rate of $3 \%$ to $4 \%$ for 2010 and it's going to reach a $0.5 \%$ yearly additional growth.
\end{abstract}

Key words: Mathematics modeling, tourism models, conceptual models, tourism demands, Tourist Area Life Cycle Theory (TALCT), dynamical system, hypothesized

\section{INTRODUCTION}

Tourism is an ancient phenomenon and it probably existed as early as when humans first inhabited earth and started travelling around but it seems that it was not till the nineteenth century that organized tourism appeared. The tourism of today known as mass tourism phenomenon started during the industrial revolution when the cost of transport over land and flying overseas became more economical. In fact, the development of air transportation led to the rapid growth of international movement of travelers (Habibi and Rahim, 2009; Seifolddini-Faranak et al., 2009; Theobald, 1998). According to the World Tourism Organization (UNWTO) the travel and tourism industry has been growing steadily worldwide since 1950 and global tourism has become more pronounced as individual wealth of citizens has increased. This has been particularly true in developed countries but more and more the idea of tourism has attracted the wealthy and middle class citizens of all countries. It is then not surprising to note that overseas visitors and tourism generally in Australia has increased over time (Fig. 1).

It is an accepted fact that the visitors or tourists do make significant impacts on global economies. The tourism sector can not only makes positive impacts but more importantly also places a number of demands on the visiting country economies. The consumption by tourists while in a country has crucial impacts such as contributing to GDP, increasing the employment rate, creating new sources of household and government income and so on. According to Australian Bureau of

Corresponding Author: S.A.H. Shobeiri Nejad, Department of Mathematics and Statistics, Environment Futures Centre, Griffith University, Brisbane Australia 
Statistic (2009), international and domestic tourism consumed approximately AUD $\$ 92$ billion from July 2007 to year-ended June 2008. It is noted that the tourism share of GDP and total employment rate were 3.6 and $4.7 \%$, respectively, during this period. Moreover, the government also gains around AUD \$7.013 billion from net taxes from related businesses. The importance of the contribution of tourism in economy has brought both public and private organizations in addition to researchers together to investigate various aspects of tourism; the positive benefits as well as negative effects of tourism demand on a country as a whole (Song and Turner, 2006).

Indeed, Li et al. (2005) noted that the majority of the published articles from 1960-2002 focused on modeling and forecasting tourism demands on countries. Success of any economic activity is facilitated by prior knowledge of the level of consumption and general nature of user demand especially during the peak times. Accurately forecasting is important particularly for forward planning and investment in major projects that facilitate tourism such as airports, theme parks, shopping centers and accommodation. All such projects are costly and in fact require a long-term approach in terms of establishing planning and financial aid. Each of these aspects in fact will in the end rely on forecast models to aid the planning process. Therefore, an accurate demand forecasting together with arrival number modeling will aid destination governments establish and carry out tourism-related strategies appropriately for long term success (Australian Bureau of Statistics, 2009b).

According to Song and Li (2008), tourist arrivals or tourist population is the most common variable to accurately measure tourism demand. This variable is usually given by the total number of tourist arrivals from an origin to a destination. One of most robust and widely discussed theory on tourism is the concept of Tourist Area Life Cycle Theory (TALCT); a conceptual framework is proposed by Butler (1980). This theory focuses on the evolution of the tourist population in a destination considering to the resources available. In the first part of this study a mathematical model is developed based. The model developed is then tested and validated for the Australian context. The calibration of the model is done using the data collected from Australian Bureau of Statistic (2009) based on a long-term period. The model is then examined in terms of stages of tourism industry and related product life cycles and its application to the modern tourist economy.

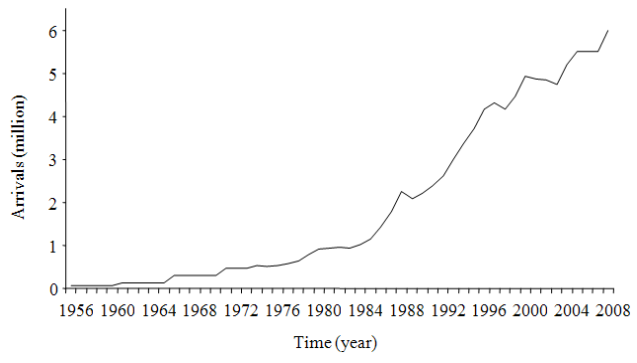

Fig. 1: Short-Term International visitors Arrivals 19562008 (Australian Bureau of Statistics-annual report of tourism industry)

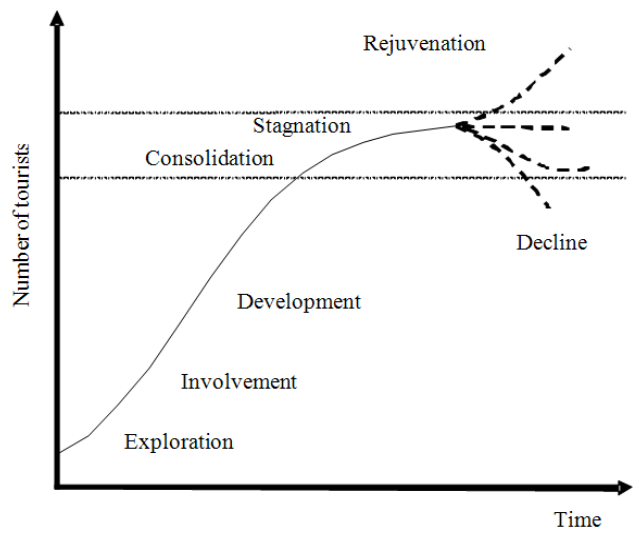

Fig. 2: The evolution of a tourist area (Adapted from Butler, 1980)

Background: Conceptual life cycle approach: Early research on tourism led to conceptualizing tourism for a destination country. In this phase of research, the evolution of tourist destination proposed in three stages including discovery, growth and decline as per Gilbert (1939) and Christaller (1963). Butler (1980) studied the conceptual life cycle approach to tourist evolution and developed in five stages (Fig. 2); namely:

- Exploration

- Involvement

- Development

- Consolidation

- Stagnation

\section{MATERIALS AND METHODS}

In the first stage of exploration tourism is not recognized as an economic activity in that only a few people travel to the destination. The local residents and government departments have little if any knowledge 
regarding policy and strategies related to tourism. Usually the destination's facilities are simple and lack much of related infrastructure systems such as a general lack of easy access to the destination site itself. The destination based tourist knowledge is lacking in that in this stage, only a few tourists have appropriate knowledge about the destination or indeed only a small group of them in fact recognize the destination as a tourist area; in the main, the knowledge is further hindered by the destination's lack of or largely undeveloped facilities.

The next stage in the cycle is labeled the involvement stage for in this stage an increased tourist numbers is noted. This in the main is due to an increased awareness of the destination as a tourist base. The local residents now also begin to realize the potential of tourism and likelihood of it being a profitable activity for the site or destination. In this light, new businesses begin to spring up encouraged by those who already provide facilities for visitors for their "stay period"; such as food and catering generally, accommodation, leisure activities and site tours. However, an increase in such activities may begin to place an undue pressures on the local community for at this stage the community may lack critical infrastructure; thus soon causing some problems for the local residents or council. The issues related to insufficient infrastructure systems such as road, airport and energy now begin to play a part and the local community then in turn begin to apply serious pressure to local politicians, governments and public departments for bids to develop and or improve the level of public infrastructure systems that are usually referred to as the enabler drivers in the tourist industry.

Given the demands placed by the locals towards the start of the so called development stage, the destination's tourism facilities in both public and private areas indeed become well developed. In fact, foreign investors and famous brands now start to engage in providing tourist demands such as accommodation. Tourism industry and local economic activities now require many skill based personnel and general labor particularly for activities related to the natural attractions of the site, cultural and other physical attractions that have now become important for development. Detailed advertising and promotional campaigns begin now and this then increases the level of the tourist knowledge of holiday destinations. In the end the tourist numbers increase often exceeding the destination population in during special events.

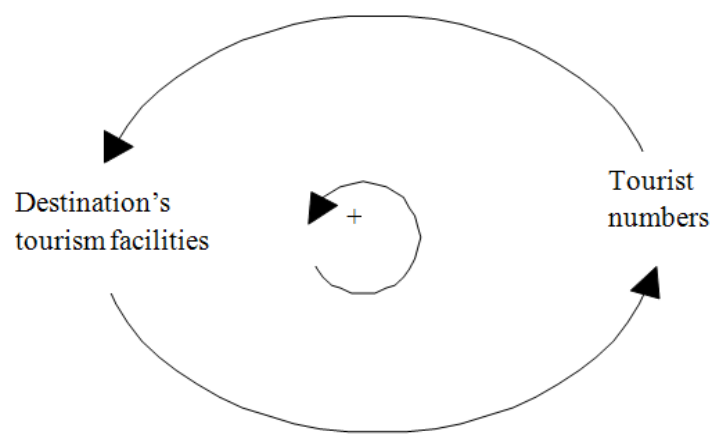

Fig. 3: The relationship between tourist numbers and tourism facilities

In the fourth consolidation stage, the tourists number continue to increase but the destination now becomes well known and thus visited by many and is now not listed as a priority by those potential tourists. The rate of growth of the tourist numbers gradually declines until finally, a stagnation stage is reached when potentially all tourists know about the destination as well as its facilities. It is seen now as a destination where there is nothing new to be discovered; the novelty has worn reaching approximately a maximum position in terms of the number of tourists. But now the destination faces a number of other issues that need control and/or regulation such as pollution of the surroundings and indeed many other social problems. Therefore, a tourist destination's viability in terms of the community relying solely on tourism related industries now needs serious attention. Butler (1980) argued two possibilities after stagnation stage, namely; rejuvenation or decline.

Butler's theory has been explored and much work has been done on the tourist area lifecycle (Hovinen, 1981; 1982; 2002; Haywood, 1986; Cooper and Jackson, 1989; Cooper, 1990; 1995; Getz (1992; Twining-Ward and Baum, 1998; Baum, 1998; Australian Bureau of Statistics, 2009a). In this study the theory is explicated in detail mathematically with novel calculations done with the model developed. The model is applied to the Australian context to study the model predictions in terms of future of Australian tourism based on a rather large data set.

Mathematical model development: It is not difficult to realize that the tourist area lifecycle is a dynamical system and one that changes over time. This suggests that a formulation in a mathematical model could be developed that contains the values of generated variables in a phase space. In this case the model framework is labeled a linear dynamical system. In this 
framework, the manner in which the processes can studied is shown in Fig. 3 that demonstrates the relationship between tourist numbers and the destination's facilities. Clearly, a number of assumptions are put forward in theoretical models and one of them is the assumption that the number of facilities at a destination increase upon increase in the tourist demand; and this in turn reciprocally influences the demand over time. That is, the demand also increases over time as a result of increase in tourism to the destination and the subsequent increase in facilities.

The formulation the dynamical system will involve defining a number of variables. For example, if we assume $\mathrm{m}$ is a constant and an independent parameter with $m>0$; $t$ is time and $x_{t}$ is the number of tourist at the destination at time t. The form can be developed by assuming new tourist numbers depend on existing destination number and an error term that depends on the existing number (allows for an increase only as $\mathrm{m}$ is greater than zero). Therefore, the number of tourists at the next time step; $t+1$ may be written as:

$$
\begin{aligned}
& \mathrm{x}_{\mathrm{t}+1}=\mathrm{x}_{\mathrm{t}}+\mathrm{mx}_{\mathrm{t}} \\
& \mathrm{x}_{\mathrm{t}+1}-\mathrm{x}_{\mathrm{t}}=\mathrm{mx}_{\mathrm{t}} \\
& \Rightarrow \dot{\mathrm{x}}_{\mathrm{t}}=\mathrm{mx}_{\mathrm{t}}
\end{aligned}
$$

while the general solution of (1) may be written as $x_{t}=$ $\mathrm{x}_{0} \mathrm{e}^{\mathrm{m}(\mathrm{t}-\mathrm{t})}$. In this case, when $\mathrm{t}=0$, the initial value of the number of tourists is greater than zero [i.e., $x_{0}>0$ ] is confirmed:

$$
x_{t}=x_{0} e^{m t}
$$

The solution as given in Eq. 2 represents the tourist numbers as a function of $t$ and the exponential type of graph represented by Eq. 2 is presented in Fig. 4.

This solution is based on Malthus' law (Bertuglia and Vaio, 2005) and the model (Eq. 1) can help explain the first three stages of Butler's theory. However, according to Butler the tourist number approaches a maximum that accounts for a flattening in numbers over time reaching the so called stagnation period. Over time a destination may not be as desired as earlier commonly due to social, economic, environmental or economic issues. Indeed, there could also be some local resentment to tourism thus impacting the destination policy. Now there are arguments that refer to negative parameters affecting the growth rate of tourist numbers. Figure 5 can be improved so that it allows for a new parameter that provides for a negative loop.

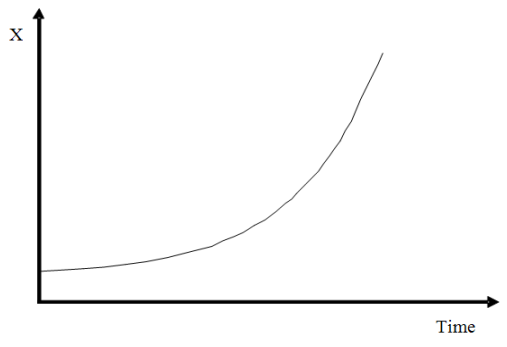

Fig. 4: Exponential growth of tourist number

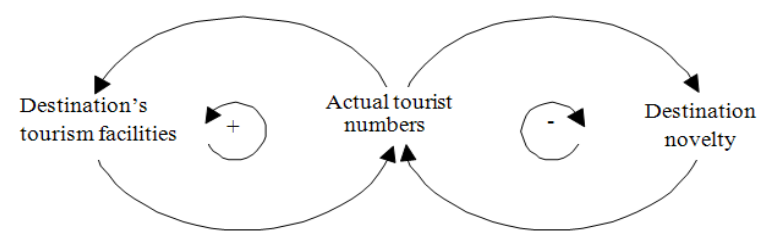

Fig. 5: Effect of negative parameter on the tourist numbers

In this dual loop, the novelty of destination over time may decrease for some particularly those who already travelled to the destination a number of times. As a consequence, tourist numbers decline and indeed Butler argued that the tourist numbers growth is not a liberal growth. The negative parameter controls the growth and ultimately the negative and positive parameters reach a balance thus indicating the peak of tourist numbers or the "capacity of growth". This phenomenon is called 'carrying capacity' which assumed and published firstly by Verhulst (1845; 1847). The combination Malthus' law and Verhulst assumption (Eq. 3) demonstrates that the tourist numbers growth at time $\mathrm{t}+1$ is proportional to:

- Constant growth rate $\mathrm{m}$ (as before)

- The tourist number at last time $\mathrm{t}$ (as before)

- The discrepancy of tourist numbers at previous time $t$ as a ratio of maximum tourist numbers here labeled $X$. That is, the growth is also now proportional to $\frac{X-x_{t}}{X}$ :

$$
\begin{aligned}
x_{t+1}=x_{t} & +m x_{t}\left(\frac{X-x_{t}}{X}\right) \\
x_{t+1}-x_{t} & =m x_{t}\left(\frac{X-x_{t}}{X}\right) \\
\dot{x}_{t} & =m x_{t}\left(\frac{X-x_{t}}{X}\right) \\
\frac{d x_{t}}{d t} & =m x_{t}\left(\frac{X-x_{t}}{X}\right) \\
& =m x_{t}-m \frac{x_{t}^{2}}{X}
\end{aligned}
$$


The solution to the differential equation developed above can be given using of the Bernoulli method:

Let $\mathrm{v}_{\mathrm{t}}=\mathrm{x}_{\mathrm{t}}^{-1}$

whose differential is:

$$
\begin{aligned}
& v_{t}^{\prime}=-x_{t}^{-2} \cdot x_{t}^{\prime} \\
& \Rightarrow> \\
& x_{t}^{\prime}=-v_{t}^{\prime} \cdot x_{t}^{2}
\end{aligned}
$$

Therefore, Eq. 3 can be written as:

$$
\mathrm{v}_{\mathrm{t}}^{\prime}+\mathrm{m} \mathrm{v}_{\mathrm{t}}=\frac{\mathrm{m}}{\mathrm{X}}
$$

whose solution can be written as:

$$
\mathrm{v}_{\mathrm{t}}=\frac{1+\mathrm{C} \cdot \mathrm{e}^{-\mathrm{mt}}}{\mathrm{X}}
$$

where, $\mathrm{C}$ is the constant let $\mathrm{C}=\mathrm{e}^{\mathrm{ma}}$ where $\mathrm{a}$ is also constant the solution may be written as:

$$
\mathrm{x}_{\mathrm{t}}=\frac{\mathrm{X}}{1+\mathrm{e}^{-\mathrm{m}(\mathrm{t}-\mathrm{a})}}
$$

Figure 6 shows tourist number growth with three different values of the parameter $m$ for a given destination. The constant parameter and the maximum capacity $X$ are both assumed to be fixed for a particularly destination.

Indeed, the new model that allows for negative effects as shown in Fig. 6 captures the stagnation period of Butler and thus provides a better model of the tourist number over time. If we let $\beta_{\mathrm{t}}=\frac{1}{1+\mathrm{e}^{-\mathrm{m}(\mathrm{t}-\mathrm{a})}}$ the solution may be written as $\frac{x_{t}}{X}=\beta_{t}$; where $\beta_{t}$ is proportion (percentage) of tourist at time $t$ to the capacity.

In a different field of industrial material science, Polli and Cook (1969) developed stages of a product life cycle using usual sigma proportions of the normal curve. Their division of stages relate closely to tourism modeling (Fig. 7a). Polli and Cook's study was based upon percentage change in real per capita product sales. Similarly, Haywood (1986) developed criteria identifying the stages also using the application of normal distribution and probabilities around the mean (Fig. 7b) and their study was based on percentage change in the number of tourists.
In fact the normal distribution models are based on product life cycle theory research (Fig. 8). Usually the life cycle comprises four stages: introduction, growth, maturity and decline.

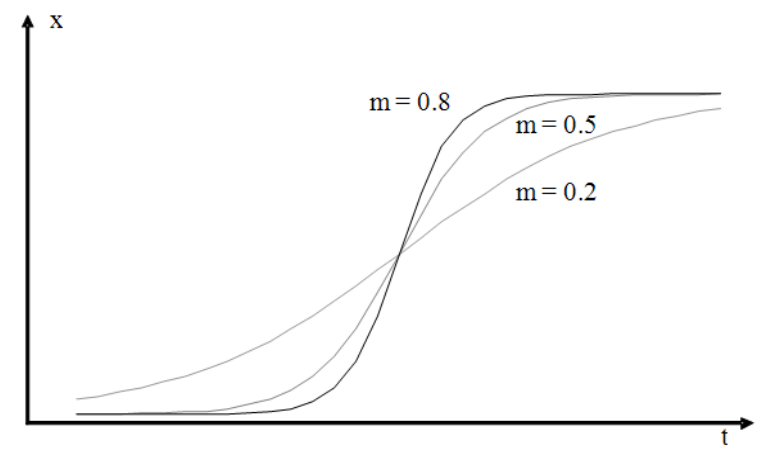

Fig. 6: The new model of Tourist number growth with negative corrective term

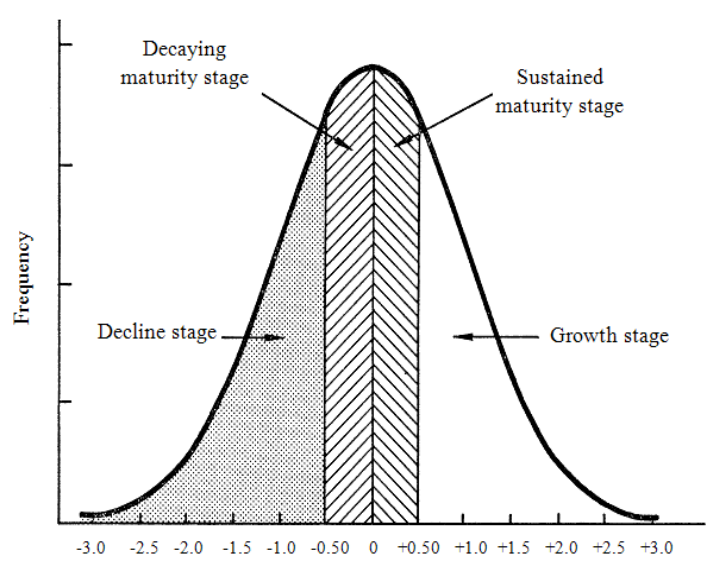

(a)

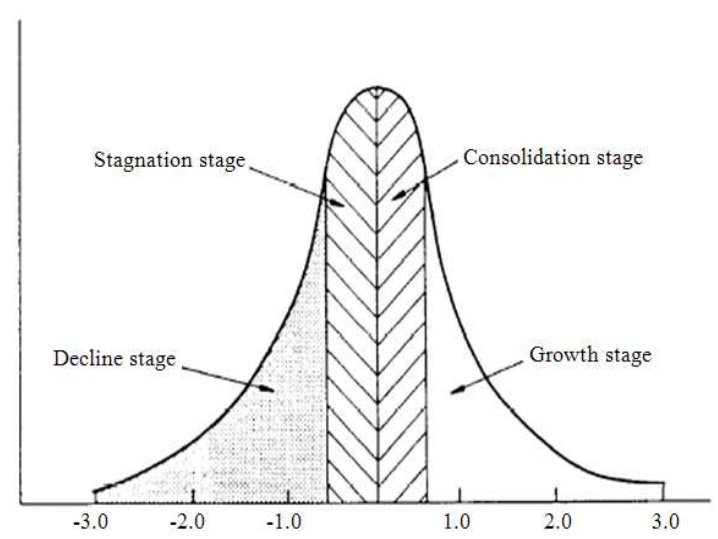

(b)

Fig. 7: (a) Percentage change in real per capita product sales Polli and Cook (1969); (b) Percentage change in the number of tourists Haywood (1986) 


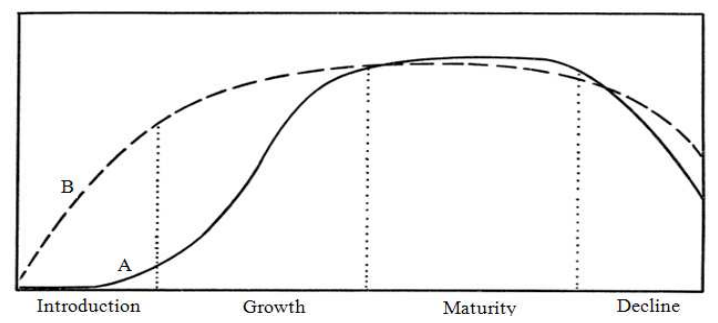

Fig. 8: Two frequently hypothesized life cycle patterns (Polli and Cook, 1969)
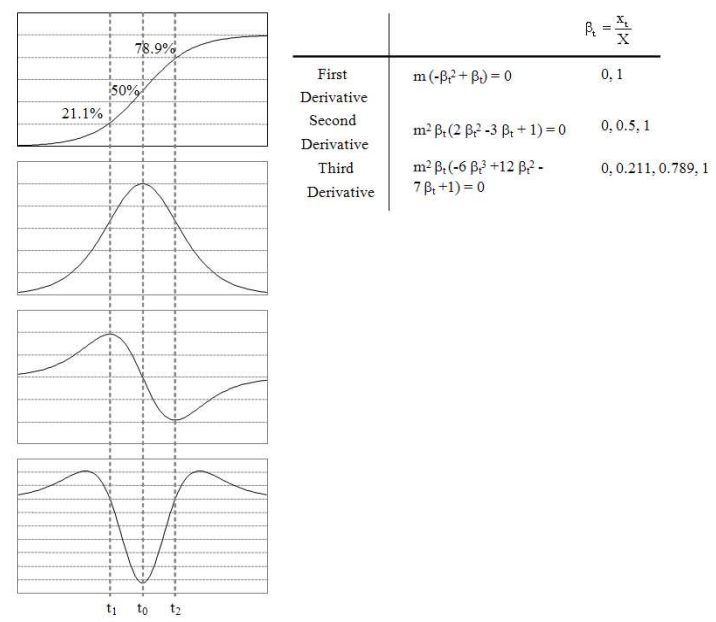

Fig. 9: Introduction, growth and maturity in product life cycle

Using this framework and ideas, it is possible to study the first three stages mentioned namely: introduction, growth and maturity stages at least using calculus; that is, by determining the first, second and third derivatives. The turning points and points of inflection and rate of rate of change can be used to determine the times at which the various stages identified in tourist modeling may be reached. In Fig. 9 calculations, the three derivatives are indentified.

The next third derivative shows the changes in acceleration's velocity (Fig. 10 and 11). In relation to introduction stage of production life cycles, Butler (1980) argued that the exploration and involvement stages are located within the introduction stage of life cycles. Figure 9 shows that there are no sign changes in the introduction stage; that is, there are no sign changes in velocity (first derivative), acceleration (second derivative) and acceleration velocity (third derivative); and all of the derivatives are noted to be positive. However, acceleration velocity change (fourth derivative) shows sign change for introduction stage from positive to negative.
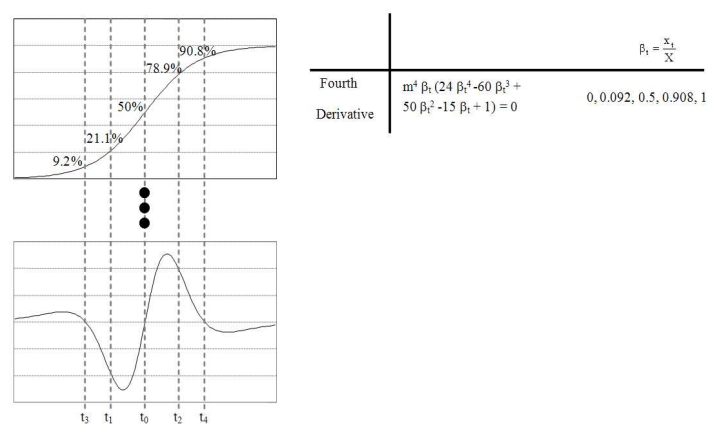

Fig. 10: The fourth derivative-change in acceleration velocity

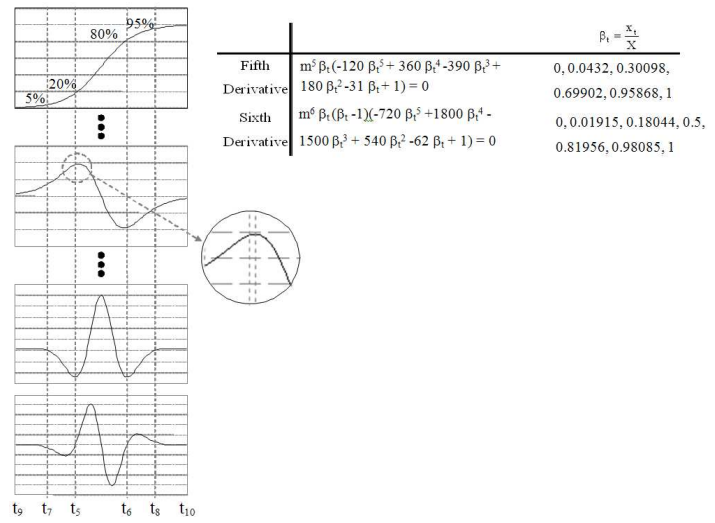

Fig. 11: The fifth and sixth derivatives

For this purpose, the fifth and sixth derivatives are used to calculate the velocity and acceleration of the fourth derivative (Fig. 10). The result of sixth derivatives is very close to fourth derivative (Fig. 11). At time $t_{1}$ (the same as $t_{5}$ ) the acceleration is approximately equal to maximum acceleration. Therefore, it can be concluded that the development stage starts at this time. The "S-shape" curve appears as a normal distribution and therefore a symmetry exists on both side of central line at time $t_{0}$. Also $t_{2}$ (the same as $t_{6}$ ) appears to be the end of development stage; and, $t_{7}$ appears to be the lowest rate of second derivative's acceleration change. Therefore, this time can be assumed to be the end of exploration stage or start of involvement stage. On the other hand, $t_{8}$ illustrates the edge between consolidation and stagnation. Therefore, the stages are approximately estimated by the fourth and fifth derivatives: $0-5,5-20,20-80,80-95$ and 95$100 \%$ (Fig. 12).

The value of $\beta_{\mathrm{t}}$ is useful for it can be used to determine the value of $\alpha$ at the critical points of stages. 
Table 1: Model determined stages and their interpretations

\begin{tabular}{|c|c|c|c|}
\hline Stage & $\mathrm{t}$ & $\frac{x_{t}}{X}$ & \\
\hline Exploration & $\mathrm{t}_{9} \leq \mathrm{t} \leq \mathrm{t}_{7}$ & $<5 \%$ & $\begin{array}{l}\text { Small number of tourists. Virgin environment. No specific } \\
\text { facilities for tourists. }\end{array}$ \\
\hline Involvement & $\mathrm{t}_{7} \leq \mathrm{t} \leq \mathrm{t}_{5}$ & $\begin{array}{l}<5 \% \\
\leq 20 \%\end{array}$ & $\begin{array}{l}\mathrm{t}_{7}-\mathrm{t}_{3}: \text { Local residents involve to tourism related business. } \\
\mathrm{t}_{3}-\mathrm{t}_{5}: \text { Pressure on Government to improve public facilities } \\
\text { supporting tourism industry. }\end{array}$ \\
\hline Development & $\mathrm{t}_{5} \leq \mathrm{t} \leq \mathrm{t}_{6}$ & $\begin{array}{l}>20 \% \\
<80 \%\end{array}$ & $\begin{array}{l}\mathrm{t}_{5}-\mathrm{t}_{1}: \text { Introduction to development. } \\
\mathrm{t}_{1}-\mathrm{t}_{7}: \text { Heavy growth. } \\
\mathrm{T}_{7}-\mathrm{t}_{6}: \text { Maturity of development. }\end{array}$ \\
\hline Consolidation & $\mathrm{t}_{6} \leq \mathrm{t} \leq \mathrm{t}_{8}$ & $\begin{array}{l}\geq 80 \% \\
\leq 95 \%\end{array}$ & $\begin{array}{l}t_{6}-t_{4}: \text { Still growing with lower rate. } \\
t_{3}-t_{5}: \text { Pressure on Government to limit the industry by oppositions. }\end{array}$ \\
\hline Stagnation & $\mathrm{t}_{8} \leq \mathrm{t} \leq \mathrm{t}_{10}$ & $>95 \%$ & Environmental, social and economic problems \\
\hline
\end{tabular}

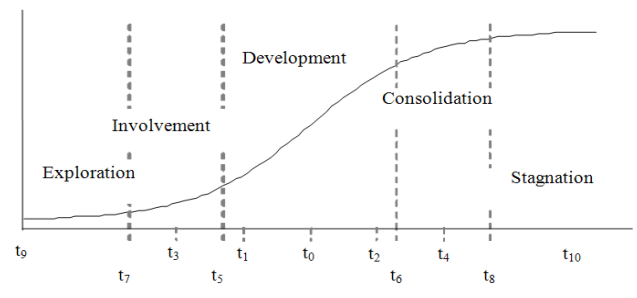

Fig. 12: five stages of destination life cycle

Equation 5 makes time variable the subject of the equation:

$$
\begin{aligned}
\beta_{\mathrm{t}}= & \frac{1}{1+\mathrm{e}^{-\mathrm{m}(\mathrm{t}-\mathrm{a})}} \\
\Rightarrow & \beta_{\mathrm{t}}\left(1+\mathrm{e}^{-\mathrm{m}(\mathrm{t}-\mathrm{a})}\right)-1=0 \\
& \ln \left(\beta_{\mathrm{t}} \cdot \mathrm{e}^{-\mathrm{m}(\mathrm{t}-\mathrm{a})}\right)=\ln \left(1-\beta_{\mathrm{t}}\right) \\
& \ln \beta_{\mathrm{t}}-\mathrm{m}(\mathrm{t}-\mathrm{a})=\ln \left(1-\beta_{\mathrm{t}}\right) \\
\mathrm{t}= & \frac{1}{\mathrm{~m}} \cdot\left[\ln \beta_{\mathrm{t}}-\ln \left(1-\beta_{\mathrm{t}}\right)\right]+\mathrm{a} \\
= & \mathrm{a}+\frac{1}{\mathrm{~m}} \ln \left[\frac{\beta_{\mathrm{t}}}{1-\beta_{\mathrm{t}}}\right]
\end{aligned}
$$

The value of the unknown value a can be found using the second derivative given the central point value is $\beta_{\mathrm{t}}=\frac{1}{2}$.

Therefore:

$$
\begin{aligned}
& 1+\mathrm{e}^{-\mathrm{m}(\mathrm{t}-\mathrm{a})}=2 \text { and } \\
& \text { At } \mathrm{t}=\mathrm{t}_{0} \\
& \mathrm{t}_{0} \text { is the time when } \mathrm{x}_{\mathrm{t}}=\frac{\mathrm{X}}{2} \\
& \Rightarrow \mathrm{e}^{-\mathrm{m}\left(\mathrm{t}_{0}-\mathrm{a}\right)}=1 \\
& \Rightarrow \mathrm{a}=\mathrm{t}_{0} \\
& \Rightarrow \mathrm{t}=\mathrm{t}_{0}+\frac{1}{\mathrm{~m}} \cdot \ln \left[\frac{\beta_{\mathrm{t}}}{1-\beta_{\mathrm{t}}}\right]
\end{aligned}
$$

The time function can now be used to determine times for the various stages identified in the conceptual model earlier and these are shown in Table 1. As shown each of the stages conceptualized can be determined using the method shown in this analysis based on calculus.

\section{RESULTS AND DISCUSSION}

The number of short-term international arrivals to Australia, which was collected from ABS website, has significantly grown since last 6 decades from about 60 000 to near 6 million arrivals per year. Before 1974, the data was collected for each five year period. This might show that the tourism in Australia was not believed to be a main economic feature for public interest. The data collection cannot be checked or procedure of collection verified and as such cannot be simply used in time series analysis (Fig. 13).

In 1978-1982 the number of the international arrivals from New Zealand grew. In 1982-1984 Australia experienced a stagnation same to the world stagnation. In late 1980s, Japan became one the top consumers of international tourism in the world, Australia was one the six most favorite tourist destinations of the Japanese population. The highest rate for Japanese tourist was noted around 1987 and 1988. After 1987 the new Japanese government started promoting their internal tourism industry within Japan, the rate of Japanese arrivals to Australia declined and finally reached a stagnation stage around 1997.

In more recent times, the Sydney Olympic Games in 2000 attracted the attention of international tourists and Australia during this period experienced a higher number of tourist numbers. However during 2001-2003 the number of tourists fell down due to a number of reasons such as: 
- Fear of economic down term led to the decline in US and Japanese arrivals

- SARS caused a fear of being affected by the diseases in flight. Australia just lost only $6 \%$ of its tourists while the Asian countries lost 20-25\%

- Iraq war has also caused fear due to terrorism and also could be considered as one of the possible reasons for the reduction in tourist number to Australia

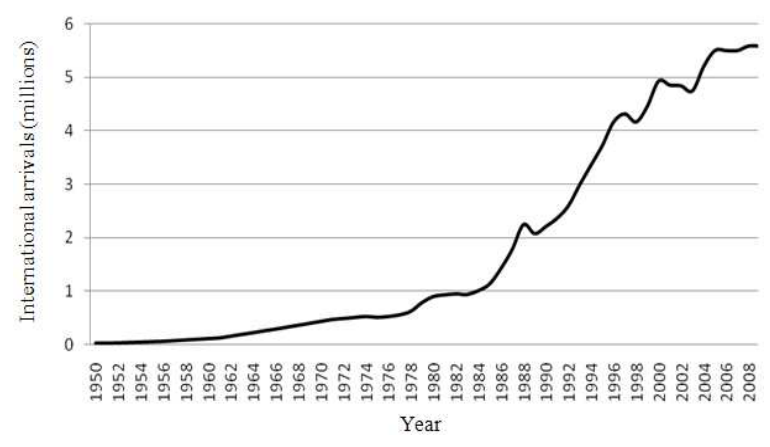

Fig. 13: Short-term international arrivals to Australia 1956-2009

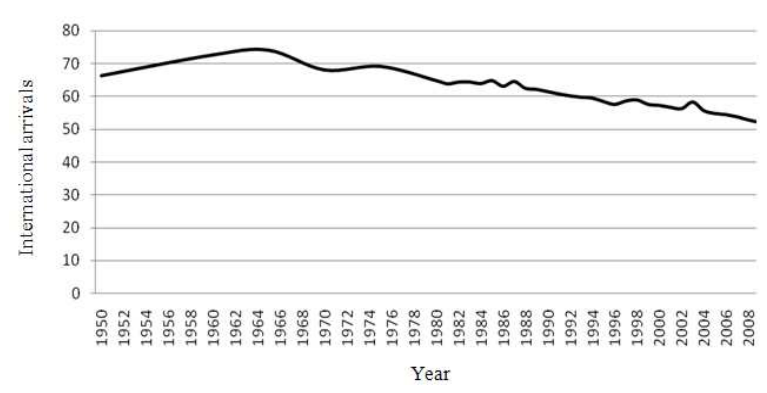

Fig. 14: Percentage share compared to the world (19502009)

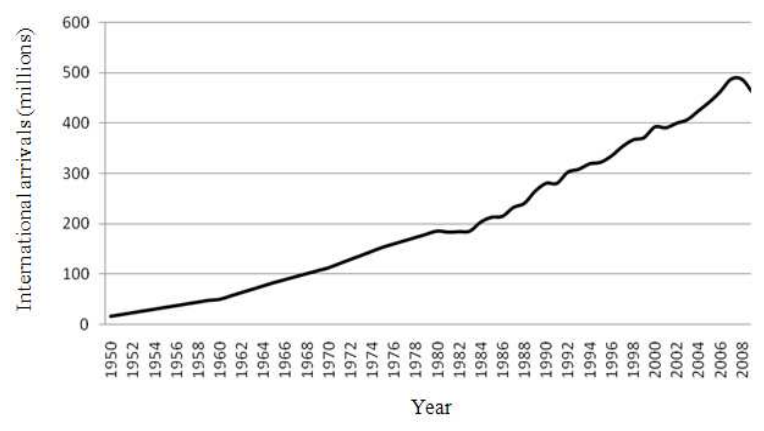

Fig. 15: Europe international arrivals 1950-2009 (UNWTO)
In 2007-2009 the number of tourists again fell down but this was a delayed effect mainly due to the global financial crises. Once again the rate of reduction in Australia was less than that noted around world and Europe.

To further understand the nature of growth of international arrivals to Australia and the number of arrivals compared to the world international movement as well as Europe more detailed analyses are needed for Europe is a well-known destination. Indeed, the tourism industry has a deep background in Europe for it is probably known as the initiator of this industry.

In fact, the data shows that Europe is the world's top tourist destination by retaining about $50 \%$ of the world's international arrivals (Fig. 14).

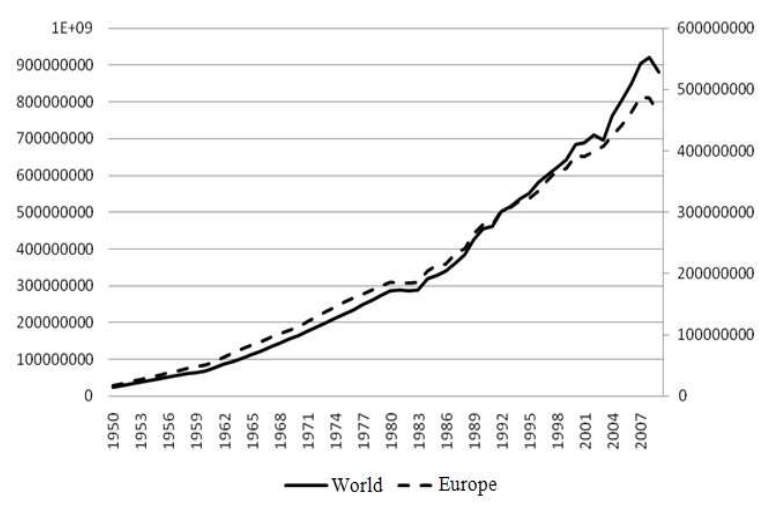

Fig. 16: Comparison of the World and Europe International Arrivals 1950-2009 (UNWTO)

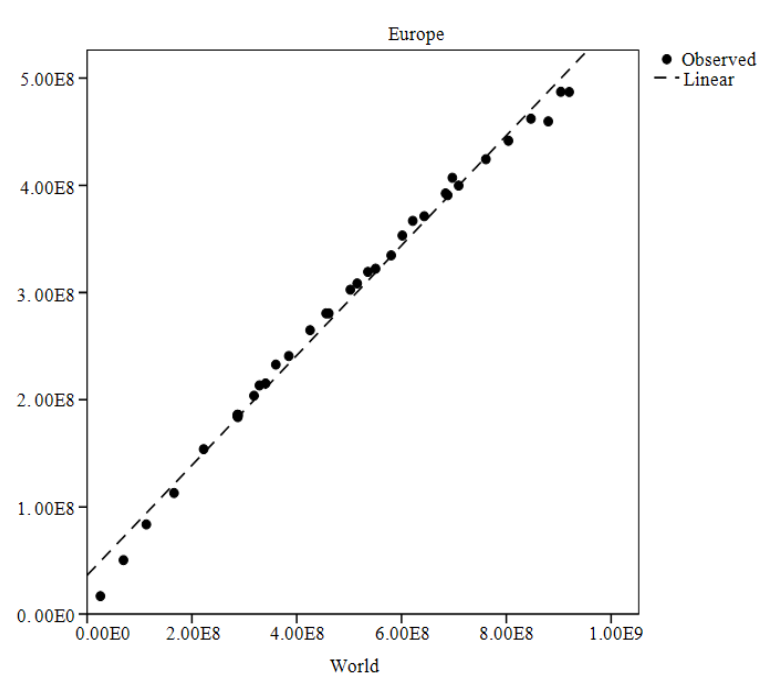

Fig. 17: Linear Regression between Europe and the world 
Figure 13 shows the significant share of Europe in the world tourism industry. Figure 15 demonstrates the Europe international arrivals since 1950 . The trend can be compared by the world's international arrivals in Fig. 16.

The average growth of the world's international arrivals is around $6.3 \%$ based on data from1950-2009. Importantly, Europe has a rate of around $5.9 \%$ for the same period. The above graphs show that although Europe has significant growth over past 6 decades this growth appears to be directly related to the world's growth. There is indeed a significant linear regression between the world and Europe (Fig. 17).

The average constant growth rate was noted to be 0.52 based on the equation with $\mathrm{R}$-squared value around 0.992. Therefore, it can be concluded that Europe has being experiencing a stagnation stage when compared to the rest of the world. However, Fig. 18 shows that during the same years Australia has being experienced a significant growth versus the world. In the same period the average growth rate for Australia is $9 \%$ which is around $150 \%$ of the world's growth.

Figure 17 shows that before 1974 the growth rate of international arrivals was growing in approximately the same manner as the world growth rate. However, speed of the Australian growth was increasing steadily and reaching a maximum around 1994. While the international arrivals continued to grow the rate of growth however, was steadily declining after the crossing time and in general closely followed the world growth level. In terms of pure numbers, in 1994 the Australian curve crossed the world curve and thus was experiencing higher arrivals than the world but again met the world curve in 2008. Nevertheless, during this uptime period a significant growth occurred in Australia. The data was analysed using logistic analysis and observation was compared with the model developed in this study (Fig. 19).

The logistic curve fitted had an R-squared value of 0.992 . The exponential was in line with the model developed in this study (Fig. 20). This shows the tourist arrivals to Australia and indeed the world can be explained using the Butler theory and the model developed.

Table 2 shows that the calculated carrying capacity for this development is 6357900 international arrivals with a growth rate is 0.144 . The turning point is half of the carrying capacity occurring around in the middle of 1993.

Based on the analysis in Table 2, the mathematical model developed earlier can be calibrated (Eq. 7) and Eq. 1 can now be written as:

$\mathrm{x}_{\mathrm{t}}=\frac{6357900}{1+\mathrm{e}^{-0.144(\mathrm{t}-1993.5)}}$

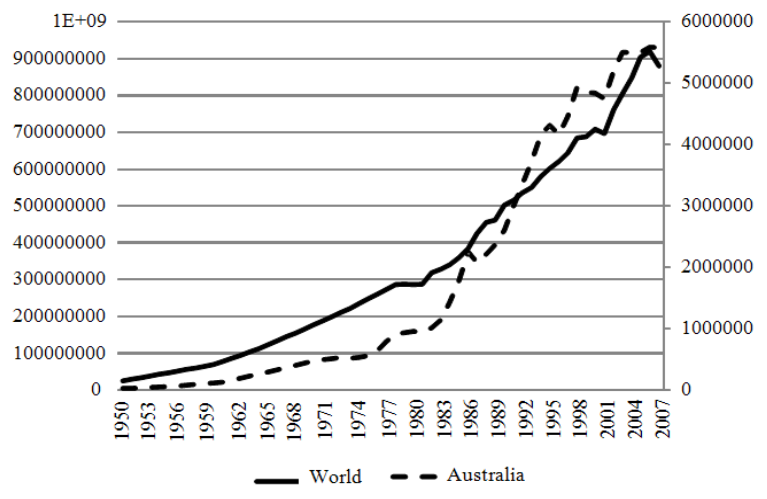

Fig. 18: Comparison of the World and Australia International Arrivals 1950-2009

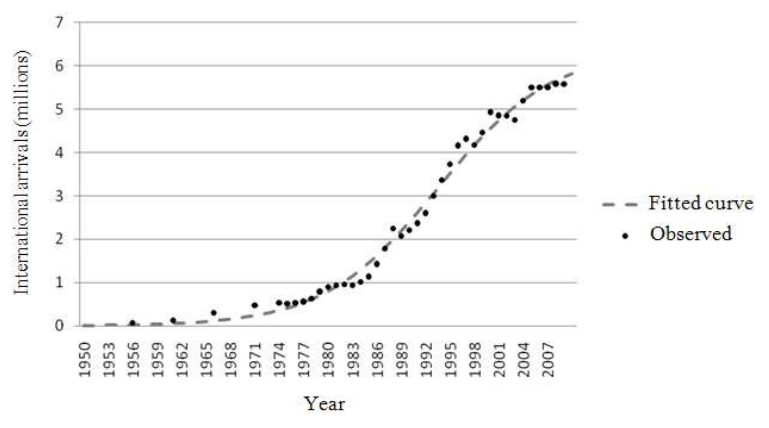

Fig. 19: Fitted growth rate and observed data

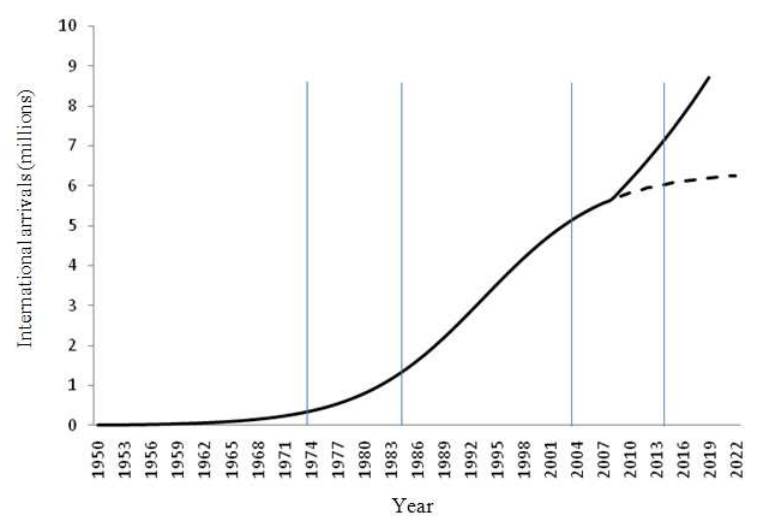

Fig. 20: Model and observed data for Australia

The model developed in this study was used to identify the following stages:

- Exploration (1973-1974)

- Involvement (1973-74-1983-84)

- Development (1983-84 to 2003-04)

- Consolidation (2003-04 to 2008)

- Stagnation (2008-dependent to the world's rate) 
J. Math. \& Stat., 6 (4): 431-441, 2010

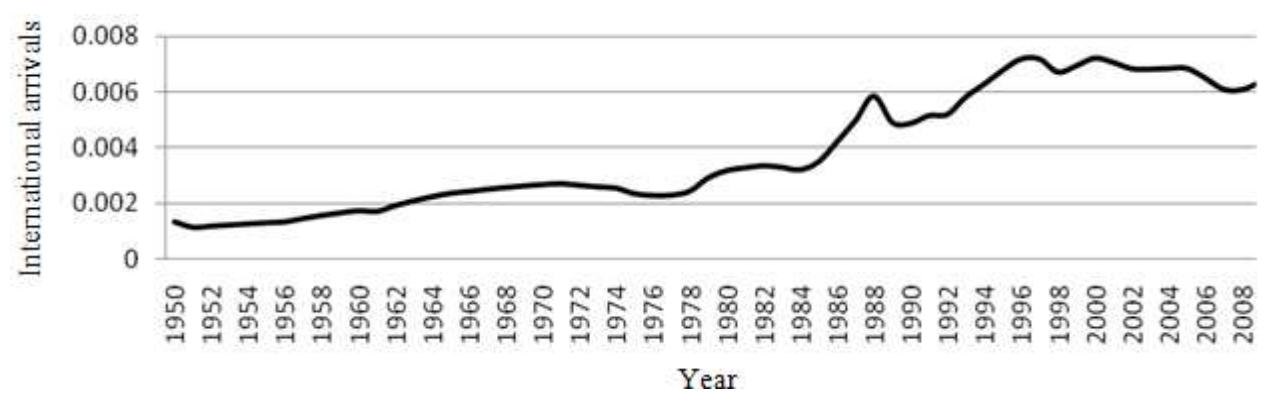

Fig. 21: Proportion of arrivals to Australia in relation to the World 1950-2009

Table 2: Parameters of the Logistic analysis

Parameter estimates

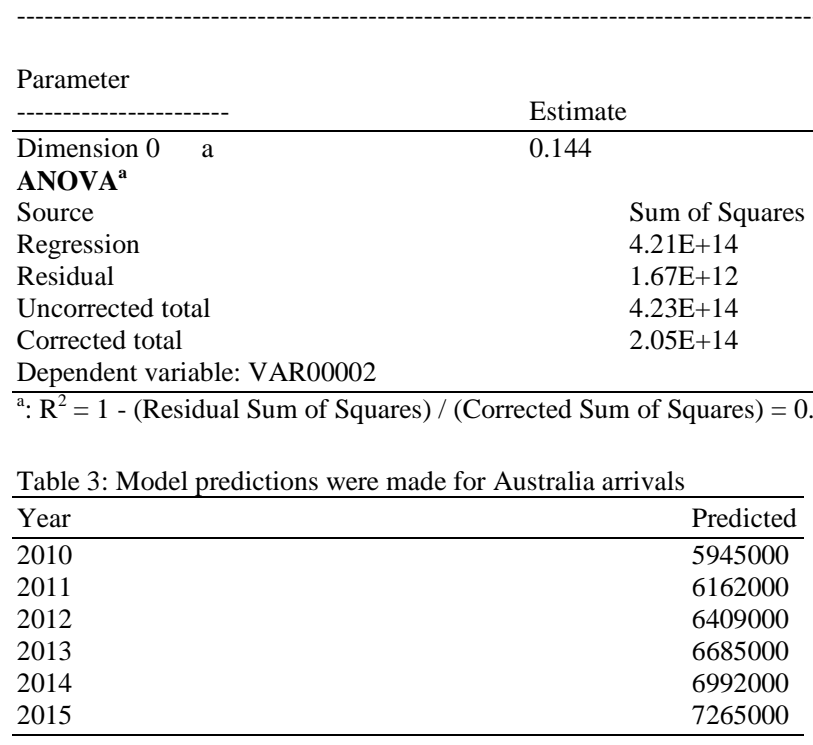

Based on the model developed predictions were made for Australia arrivals and this is shown in Table 3.

A further investigation shows that the proportion of Australian international arrivals (in relation to the world international arrivals) has grown more than three times (from 0.02\%-0.061) during the last 6 decades (Fig. 21). In contrast, the proportion of Europe to the world remains without significant changes.

\section{CONCLUSION}

In this study a mathematical model of tourist arrivals was developed and analyzed based on the Bulter's conceptual model and product life cycle frameworks. The model developed was analysis theoretically and calibrated using real Australian tourist arrival data. Using calculus of derivatives, the model was used to identify the stages identified in the conceptual model: Bulter framework. The model helped

determine time periods of the following stages: exploration, involvement, development, consolidation and stagnation (Table 2 and Fig. 2). Based on the analyses done in this study, the model predicts growth to be at least at the world growth rate and predicts around 7.2 million arrivals in 2015. Moreover, there appears to be a healthy rejuvenation rate that is a figure that may be used in forward planning for example. More specifically, the analyses of the tourist arrival data establish a number of facts such as:

- The international arrivals to Australia have been grown significantly since 1974

- The growth has a logistic trend as predicted by the theoretical model and it seems that the stagnation period of Australia is yet to come thus many opportunities exist in the tourism industry

- The present proportion of Australian arrival to the world is around $0.061 \%$ suggesting much can be still done regarding attraction of the tourist dollar

- The model curve showed the critical regions identified and the data shows the trend is again becoming stable but will be dependent to the world rate as expected

- In critical region and before stagnation, it is predicted that Australia will have a growth equal to the world's rate 
- According to UNWTO, the world has a growth rate of $3-4 \%$ for 2010 and it's going to reach $0.5 \%$ growth

- This model also shows that the reliable rate for further development when compared to the world (Rejuvenation to Stagnation) is 0.144 that may also be seen as the growth of tourist awareness and interest for new investment and development; useful information for longer term planners and government departments

\section{REFERENCES}

Australian Bureau of Statistics, 2009a. Australian National Accounts: Tourism Satellite Account 2008-2009, 5249.0 ABS: Canberra. http://www.abs.gov.au/AUSSTATS/abs@.nsf/MF/ 5249.0

Australian Bureau of Statistics, 2009b. Year Book Australia, 2009-10. (No 1301.0). Canberra, Australian Capital Territory.

Baum, T., 1998. Tourism Marketing and the Small Island Environment: Cases from the Periphery. In: Embracing and Managing Change in Tourism, Laws, E. et al. (Eds.). Routledge, London, pp: 433. http://www.amazon.com/gp/search?index=books\&l inkCode $=$ qs \&keywords $=0415159989$

Bertuglia, C.S. and F. Vaio, 2005. Nonlinearity, Chaos and Complexity. 1st Edn., The Dynamics of Natural and Social Systems. Oxford University Press, Oxford, pp: 387. ISBN: 0-19-856790-1

Butler, R.W., 1980. The concept of a tourist area cycle of evolution: Implications for management of recourse. Canadian Geographer, 24: 5-12. DOI: 10.1111/j.1541-0064.1980.tb00970.x

Christaller, W., 1963. Some considerations of tourism location in Europe: The peripheral regionsunderdeveloped countries-recreation areas. Proceed. Reg. Sci., 12: 95-105. DOI: 10.1007/BF01941243

Cooper, C. and S. Jackson, 1989. Destination life cycle: The isle of man case study. Annals Tourism Res., 16: 377-398. DOI: 10.1016/0160-7383(89)90051-0

Cooper, C., 1990. Resorts in decline-The management response. Tourism Manage., 11: 63-67. Doi: 10.1016/0261-5177(90)90009-X

Cooper, C., 1995. Strategic planning for sustainable tourism: The case of offshore islands in the UK. J. Sustain. Tourism, 3: 191-209. DOI: 10.1080/09669589509510726

Getz, D., 1992. Tourism planning and the destination life cycle. Annals Tourism Res., 19: 752-770. DOI: 10.1016/0160-7383(92)90065-W
Gilbert, E.W., 1939. The growth of inland and seaside health resorts in England. Scottish Geograp. Mag., 55: 16-35. DOI: 10.1080/00369223908735100

Habibi, F. and K.A. Rahim, 2009. A Bound Test Approach to Cointegration of Tourism Demand. Am. J. Applied Sci., 6: 1924-1931. DOI: 10.3844/.2009.1924.1931

Haywood, K.M., 1986. Can the tourist-area life cycle be made operational? Tourism Manage., 7: 154-167. DOI: $10.1016 / 0261-5177(86) 90002-6$

Hovinen, G., 1982. Visitor cycles: Outlook in tourism in Lancaster county. Annal. Tourism Res., 9: 565-583. DOI: 10.1016/0160-7383(82)90073-1

Hovinen, G., 1981. A tourist cycle in Lancaster county, Pennsylvania. Canadian Geographer, 25: 283-286. DOI: 10.1111/j.1541-0064.1981.tb01649.x

Hovinen, G., 2002. Revisiting the destination lifecycle model. Annal. Tourism Res., 29: 209-230. DOI: 10.1016/S0160-7383(01)00036-6

Li, G., H. Song and S.F. Witt, 2005. Recent developments in econometric modeling and forecasting. J. Travel Res., 44: 82-99. http://jtr.sagepub.com/content/44/1/82.short

Polli, R. and V. Cook, 1969. Validity of the product life cycle. J. Bus., 42: 385-400. http://ideas.repec.org/a/ucp/jnlbus/v42y1969i4p385 $-400 . h t m l$

Seifolddini-Faranak, M., S. Fard and H. Ali, 2009. Distribution and Determining of Tourist Attractions and Modeling of Tourist Cities for the City of Isfahan-Iran. Am. J. Econo. Bus. Admin., 1: 160-166. DOI: 10.3844/.2009.160.166

Song, H. and G. Li, 2008. Tourism Demand Modeling and Forecasting. Tourism Manage., 29: 203-220. http://epubs.surrey.ac.uk/1085/1/fulltext.pdf

Song, H. and L. Turner, 2006, Tourism Demand Forecasting. In: International Handbook on the Economics of Tourism, Dwyer, L. and P. Forsyth (Eds.). Cheltenham, Edward Elgar, ISBN: 184720984X

Theobald, W.F., 1998. Global Tourism. 2nd Edn., Butterworth-Heinemann, Oxford, pp: 503. ISBN: 0-7506-4022-7

Twining-Ward, L. and T. Baum, 1998. Dilemmas facing mature island destinations: cases from the Baltic. Progress Tourism Hospitality Res., 4: 131-140. DOI: 10.1002/(SICI)1099-1603(199806)

Verhulst, P.-F., 1845. Recherches mathématiques sur la loi d'accroissement de la population. Nouv. mém. de l'Academie Royale des Sci. et Belles-Lettres de Bruxelles 18: 1-41.

Verhulst, P.-F., 1847. Deuxième mémoire sur la loi d'accroissement de la population. Mém. de l'Academie Royale des Sci., des Lettres et des Beaux-Arts de Belgique, 20: 1-32. 